Gut, 1963, 4, 378

\title{
Active 'juvenile' cirrhosis considered as part of a systemic disease and the effect of corticosteroid therapy
}

\author{
A. E. READ ${ }^{1}$, SHEILA SHERLOCK ${ }^{2}$, AND C. V. HARRISON ${ }^{3}$ \\ From the Departments of Medicine, University of Bristol, \\ Postgraduate Medical School of London, \\ and the Royal Free Hospital School of Medicine, and the Department of \\ Morbid Anatomy, Postgraduate Medical School of London
}

EDITORIAL SYNOPSIS This is a clinical study of 81 patients (32 male and 49 female), who are not alcoholics, with jaundice of hepato-cellular type lasting longer than three months. Forty-nine of these patients were under 21 years of age. The natural history of the condition and the response to corticosteroid therapy is described; good symptomatic relief can be achieved with corticosteroids but they do not seem to prolong life. The aetiology is discussed with special reference to the relationship to viral hepatitis, to systemic lupus erythematosus, and to other disturbances of immunity.

There are several reports in the world literature describing a chronic variety of liver disease occurring mainly in young adult patients (Waldenström, 1950; Bearn, Kunkel, and Slater, 1956; Naish, 1960; Willocx and Isselbacher, 1961). This paper describes the clinical and pathological features seen in a group of 81 patients considered to belong to this group. In particular, the effect of treatment with corticosteroid drugs is described. Previous authors have used a variety of descriptive terms for this syndrome. We decided that our criterion of inclusion should be chronic jaundice of hepatocellular type lasting

'Department of Medicine, University of Bristo

${ }^{2}$ Department of Medic:ne, Royal Free Hospital, London

${ }^{3}$ Department of Morbid Anatomy, Postgraduate Medical School of London longer than three months. This would then exclude all the usual patients with acute viral hepatitis and patients with established portal or post-necrotic cirrhosis without jaundice. We also excluded patients who had a high alcoholic intake. We initially restricted our series to those less than 40 years old, for most patients seemed to be well below this age but older groups outside this age range have since been included because of their clinical similarity.

Eighty-one patients were studied, 70 being less than 40 years old (Fig. 1). Forty-nine were female and 32 male. When contrasted with patients with established post-necrotic and portal cirrhosis, but without jaundice, certain differences were evident (Fig. 1). In the icteric group there was a predomin-

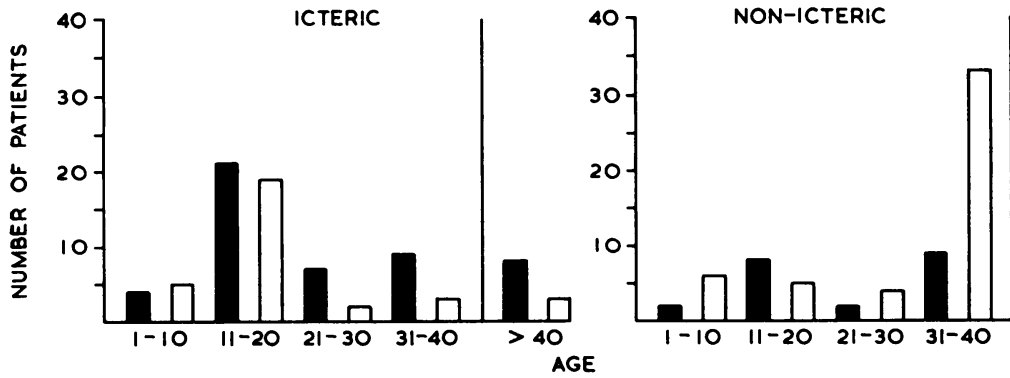

Open blocks are males, dense blocks females, the two groups were seen concurrently.
FIG. 1. The age and sex distribution of younger patients seen with (81) and without (69) hepato-cellular jaundice lasting longer than three months. Note that the incidence in the icteric group is maximum between 11 and 20 years, and the sex incidence is equal. In the nonicteric group, males predominate over the age of 30 years. 
ance of women, and 21 of the 49 women and 19 of the 32 men were between 11 and 20 years of age. In the group with established cirrhosis under the age of 40 without icterus, seen during a similar period and numbering 69 patients, 48 were male. Of this group 42 (33 males and nine females) were between the ages of 31 and 40 years. None of these patients were alcoholics.

\section{CLINICAL FEATURES}

In many patients jaundice had persisted longer than three months. It had lasted longer than two years in 24 patients and in one patient more than 15 years. Icterus was variable in degree but usually mild or moderate (serum bilirubin $1-10 \mathrm{mg} \%$ ). The onset was often difficult to define, but in 23 of the 81 patients it seemed to begin as an attack of viral hepatitis. An acute onset, contact with viral hepatitis, or an illness commencing with general malaise and upper gastrointestinal symptoms were suggestive features. Thirty patients were seen in whom the onset of jaundice was insidious and constitutional symptoms mild unless deep jaundice developed. In five the disease started as a gastrointestinal upset. In two patients severe abdominal pain preceded the onset of jaundice and in one of these a laparotomy was done because the picture simulated surgical jaundice. Five patients developed jaundice during pregnancy, and in one patient pregnancy was terminated because of it. In three patients pregnancy proceeded to a normal termination, one patient showing a relapse of jaundice in the puerperium. In one other patient jaundice developed three days after a surgical operation (thyroidectomy). In two others the condition presented as ascites.

Thirteen patients presented with a preceding illness in some organ other than the liver. Two patients had preceding Hashimoto's disease, three others diabetes, and three a respiratory infection or pneumonia. Three had preceding ulcerative colitis. One patient had an acute illness diagnosed on good clinical and serological evidence as acute rheumatic fever, and yet another patient had a preceding 'rheumatoid-like' arthritis. Six patients had had viral hepatitis many years before the onset of the present illness.

\section{PHYSICAL FINDINGS}

The picture was usually that of liver cell jaundice in young, often remarkably well-looking and well-built young adults (Fig. 2). There was usually palpable enlargement of the spleen (62 patients). In 15 patients there was no palpable splenomegaly

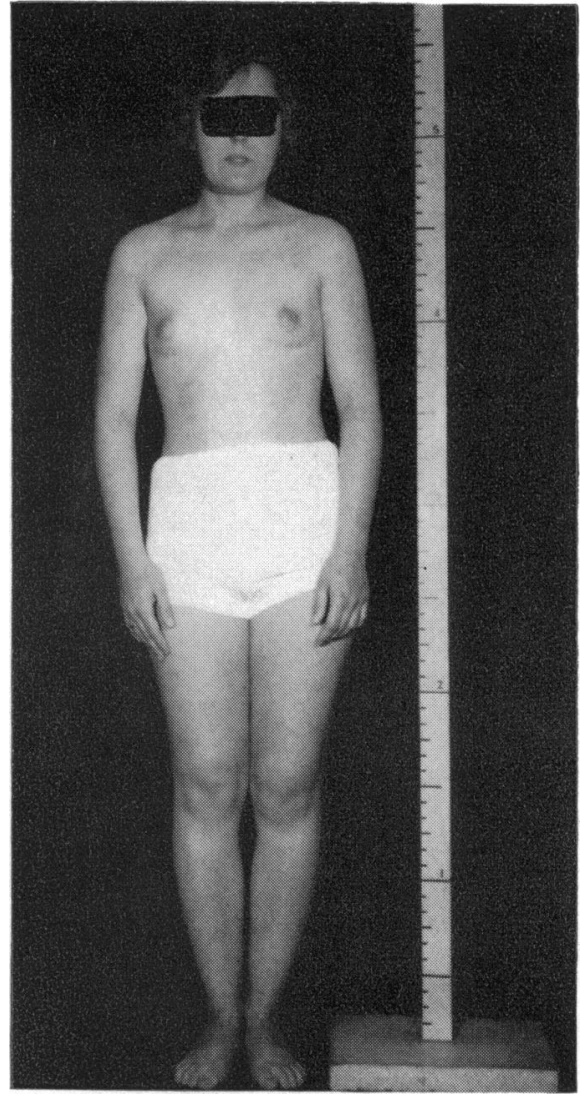

FIG. 2. Young female patient (case 43). Note good nutrition and height.

although in four of these impaired percussion over the splenic area suggested some enlargement.

Liver size was variable. In 58 patients there was palpable enlargement. In 17 patients the liver was not enlarged and in six, who had had a protracted course, it was probably reduced in size.

Cutaneous stigmata of liver cell disease were common, spider naevi being found in almost every patient. Cutaneous striae were a feature in some patients even before steroid therapy (Fig. 3). Gynaecomastia was noted in young male patients.

Nine patients bled from oesophageal varices and in six of these a portacaval anastomosis was necessary. Eight other patients showed varices radiologically but had not bled. Twelve patients developed ascites as a later complication. Attacks of pyrexia were common. Six patients in whom fat balance studies were performed showed steatorrhoea.

Amenorrhoea was almost universal in the young women. Jaundice and general malaise increased with a menstrual period. Amenorrhoea was variable and 


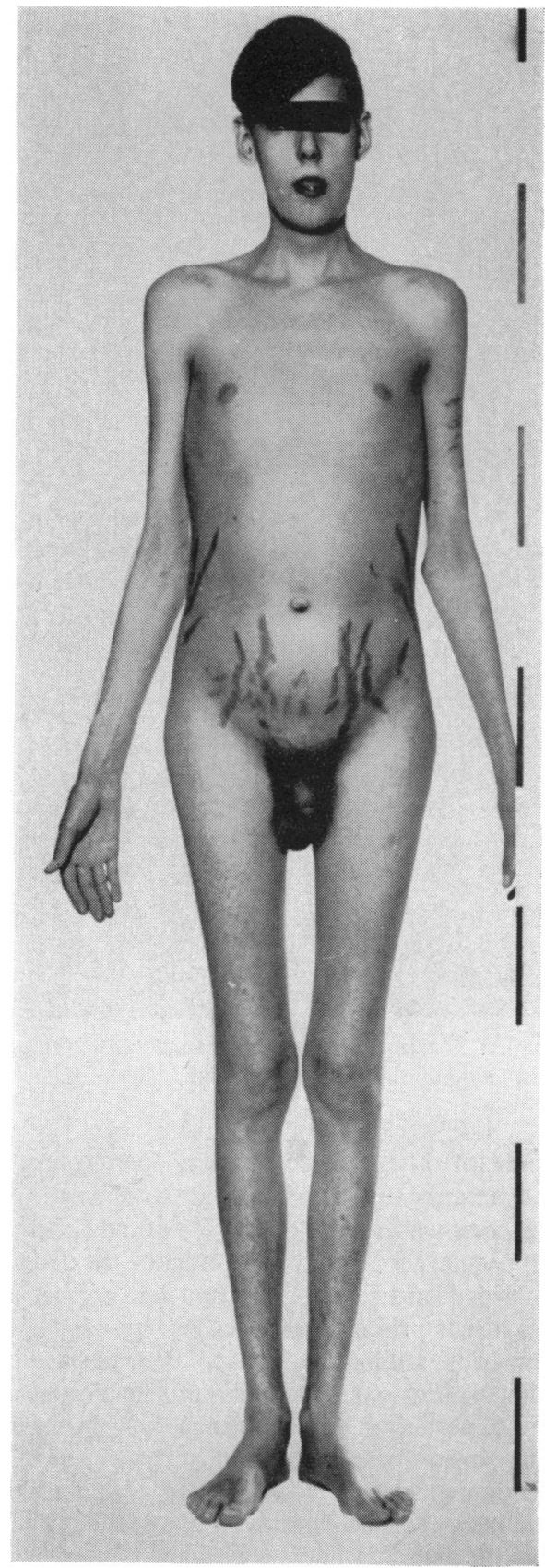

FIG. 3

FIG. 3. Young male patient (case 17). Note striae on abdomen and upper arm.

FIG. 4. Purpuric eruption over ankles and dorsum of foot (case 43). tended to remit when evidence of liver cell disease disappeared either spontaneously or as a result of treatment.

One patient had Wilson's disease (case 1, Sherlock, 1961).

A further group of clinical features seemed to bear little connexion with the hepatic lesion (Table 1).

Skin rashes were seen in 22 patients: 14 of these patients had severe acne and four others had erythematous skin lesions. In two patients a dermatological diagnosis of lupus erythematosus was made. Two patients had purpura and one of them showed a purpuric eruption over the legs (Fig. 4) with splinter haemorrhages under the nails and at the nail bases.

Arthralgia was a feature in nine patients and one patient had a chronic polyarthritis indistinguishable clinically from rheumatoid arthritis but with a negative differential agglutination reaction. One patient had symptoms of spondylitis without radiological changes in the spine or sacro-iliac joints but a positive differential agglutination test. Arthralgia was usually seen when the liver lesion was clinically active.

Two patients showed generalized lymphadenopathy.

Thirteen patients developed pulmonary infiltrations, chest infection, or pulmonary collapse. Frank lobar or lobular pneumonia, pyrexia with fleeting shadows on the chest radiograph, lobar collapse of the lung, hilar adenitis, and chronic

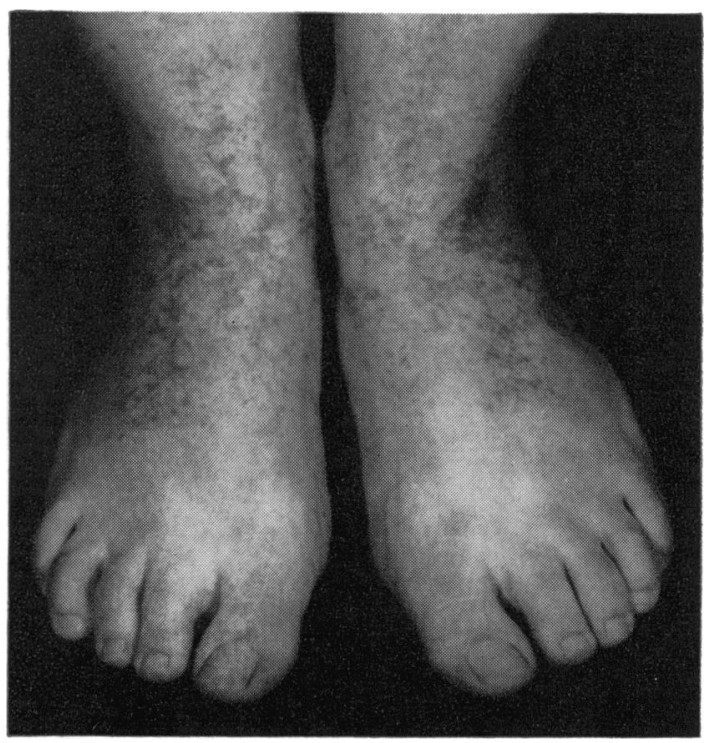

FIG. 4 
TABLE I

SUMMARY OF THE REPORTED SERIES

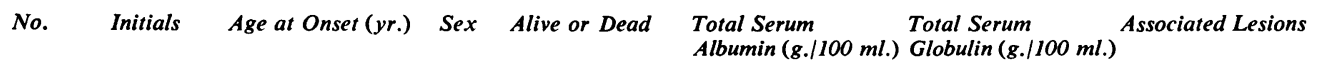

\begin{tabular}{|c|c|c|c|c|c|c|c|}
\hline 1 & J.M. & 18 & $\mathbf{M}$ & $\mathbf{A}$ & $2 \cdot 4$ & 4.9 & \\
\hline 2 & W.M. & 16 & $\mathbf{M}$ & $\mathbf{A}$ & 3.5 & $3 \cdot 1$ & Skin rash, gynaecomastia, acne \\
\hline 3 & P.H. & 19 & $\mathbf{M}$ & $\mathbf{D}$ & 1.7 & $4 \cdot 1$ & Gynaecomastia, epilepsy, acne \\
\hline $4^{1}$ & A.D. & 20 & $\mathbf{M}$ & $\mathbf{D}$ & $2 \cdot 8$ & $4 \cdot 5$ & \\
\hline 5 & A.K. & 32 & $\mathbf{M}$ & $\mathbf{D}$ & 3.9 & $3 \cdot 2$ & \\
\hline 6 & B.L. & 18 & $\mathbf{M}$ & $\mathbf{D}$ & $2 \cdot 1$ & 5.9 & $\begin{array}{l}\text { Gynaecomastia, lobar pneu- } \\
\text { monia, acne }\end{array}$ \\
\hline 7 & A.W. & 9 & $\mathbf{M}$ & D & $3 \cdot 5$ & $5 \cdot 2$ & \\
\hline $8^{1}$ & L.H. & 31 & $\mathbf{M}$ & $\mathbf{A}$ & $2 \cdot 7$ & $6 \cdot 6$ & Arthralgia, L.E. cells \\
\hline $9^{1}$ & A.S. & 25 & $\mathbf{M}$ & $\mathbf{D}$ & $2 \cdot 7$ & $6 \cdot 2$ & $\begin{array}{l}\text { Psychosis, lupus skin lesion, } \\
\text { renal tubular acidosis, } \\
\text { albuminuria, L.E. factor }\end{array}$ \\
\hline $10^{1}$ & P.J. & 63 & $\mathbf{M}$ & $\mathbf{A}$ & $3 \cdot 7$ & $5 \cdot 2$ & $\begin{array}{l}\text { Urinary infection, pleurisy, } \\
\text { skin rash }\end{array}$ \\
\hline $11^{1}$ & A.B. & 40 & $\mathbf{M}$ & $\mathbf{D}$ & $4 \cdot 3$ & $4 \cdot 6$ & \\
\hline 12 & P.B. & 54 & $\mathbf{M}$ & $\mathbf{A}$ & 3.4 & $5 \cdot 0$ & \\
\hline $13^{1}$ & A.S. & 25 & $\mathbf{M}$ & $\mathbf{A}$ & $4 \cdot 2$ & 4.4 & Urinary infection, L.E. cells \\
\hline $14^{2}$ & M.F. & 15 & $\mathbf{M}$ & $\mathbf{A}$ & $4 \cdot 3$ & $6 \cdot 0$ & \\
\hline $15^{1}$ & M.E. & 11 & $\mathbf{M}$ & $\mathbf{A}$ & $3 \cdot 5$ & $2 \cdot 8$ & \\
\hline $16^{1}$ & A.K. & 15 & $\mathbf{M}$ & A & $2 \cdot 8$ & $7 \cdot 6$ & \\
\hline $17^{1}$ & J.L. & 17 & $\mathbf{M}$ & $\mathbf{A}$ & $2 \cdot 7$ & $4 \cdot 2$ & Spondylitis \\
\hline $18^{1}$ & K.R. & 8 & $\mathbf{M}$ & D & $2 \cdot 5$ & 3.9 & \\
\hline 19 & B.A. & 14 & $\mathbf{M}$ & D & $3 \cdot 6$ & $5 \cdot 6$ & Hepatoma \\
\hline $20^{1}$ & A.A. & 18 & $\mathbf{M}$ & $\mathbf{A}$ & $3 \cdot 6$ & $5 \cdot 1$ & Lymphadenopathy \\
\hline 21 & C.B. & 11 & $\mathbf{M}$ & $\mathbf{D}$ & $1 \cdot 7$ & $4 \cdot 8$ & Potassium-losing kidney \\
\hline $22^{1}$ & J.H. & 14 & $\mathbf{M}$ & $\mathbf{A}$ & $4 \cdot 4$ & 4.9 & \\
\hline 23 & P.L. & 17 & $\mathbf{M}$ & $\mathbf{A}$ & $3 \cdot 2$ & 6.8 & Diabetes \\
\hline 24 & G.M. & 10 & $\mathbf{M}$ & A & $4 \cdot 1$ & 4.4 & Ulcerative colitis \\
\hline $25^{1}$ & P.W. & 16 & $\mathbf{M}$ & $\mathbf{A}$ & $3 \cdot 0$ & $3 \cdot 4$ & Acne \\
\hline $26^{1}$ & T.W. & 6 & $\mathbf{M}$ & $\mathbf{A}$ & 1.9 & $4 \cdot 2$ & Ulcerative colitis, gynaecomastia \\
\hline $27^{1}$ & P.W. & 12 & $\mathbf{M}$ & D & $3 \cdot 6$ & $5 \cdot 0$ & $\begin{array}{l}\text { Urinary infection, potassium- } \\
\text { losing kidney, L.E. cells, acne }\end{array}$ \\
\hline $28^{1}$ & E.B. & 15 & M & $\mathbf{A}$ & $3 \cdot 1$ & $3 \cdot 9$ & $\begin{array}{l}\text { Pneumonia, acne, lymphadeno- } \\
\text { pathy }\end{array}$ \\
\hline 291 & Q.P. & 15 & $\mathbf{M}$ & $\mathbf{A}$ & 3.4 & $4 \cdot 4$ & Cerebral vasculitis \\
\hline $30^{1}$ & F.W. & 9 & $\mathbf{M}$ & $\mathbf{A}$ & $3 \cdot 0$ & 3.9 & Gynaecomastia \\
\hline 31 & A.W. & 15 & $\mathbf{M}$ & $\mathbf{A}$ & $3 \cdot 2$ & $4 \cdot 8$ & \\
\hline $32^{1}$ & P.W. & 54 & $\mathbf{M}$ & $\mathbf{A}$ & $2 \cdot 5$ & $6 \cdot 0$ & Arthralgia \\
\hline 33 & S.B. & 4 & $\mathbf{F}$ & $?$ & $3 \cdot 8$ & $6 \cdot 1$ & Mottled lung fields \\
\hline $34^{1}$ & E.C. & 13 & $\mathbf{F}$ & D & $2 \cdot 9$ & $4 \cdot 2$ & Pneumonia, pleurisy, acne \\
\hline $35^{1}$ & B.Y. & 14 & $\mathbf{F}$ & $\mathbf{A}$ & $3 \cdot 0$ & $7 \cdot 2$ & Recurrent chest infection \\
\hline $36^{1}$ & N.S. & 2 & $\mathbf{F}$ & $\mathbf{D}$ & $1 \cdot 5$ & $8 \cdot 2$ & $\begin{array}{l}\text { L.E. cells, arthralgia, urinary } \\
\text { infection, lupus kidney, } \\
\text { malignant hypertension }\end{array}$ \\
\hline $37^{1}$ & P.T. & 14 & $\mathbf{F}$ & $\mathbf{A}$ & $3 \cdot 1$ & $5 \cdot 5$ & $\begin{array}{l}\text { Acne, autoimmune haemolytic } \\
\text { anaemia }\end{array}$ \\
\hline 38 & A.O. & 16 & $\mathbf{F}$ & $\mathbf{A}$ & $3 \cdot 2$ & $7 \cdot 4$ & \\
\hline 39 & E.K. & 17 & $\mathbf{F}$ & $\mathbf{A}$ & $4 \cdot 2$ & $5 \cdot 3$ & Bronchiectasis \\
\hline 40 & K.H. & 23 & $\mathbf{F}$ & D & $3 \cdot 7$ & $5 \cdot 2$ & $\begin{array}{l}\text { Acne, L.E. cells, depressive } \\
\text { psychosis, myxoedema; post- } \\
\text { mortem ovarian atrophy, Crookes' } \\
\text { cell change in pituitary }\end{array}$ \\
\hline $41^{1}$ & A.G. & 17 & $\mathbf{F}$ & $\mathbf{D}$ & $3 \cdot 1$ & $5 \cdot 6$ & $\begin{array}{l}\text { Albuminuria, nephrotic syndrome, } \\
\text { arthralgia }\end{array}$ \\
\hline $42^{1}$ & S.S. & 22 & $\mathbf{F}$ & $\mathbf{D}$ & $2 \cdot 9$ & $4 \cdot 8$ & $\begin{array}{l}\text { Skin rash, albuminuria, } \\
\text { pneumonia. left pleural effusion }\end{array}$ \\
\hline $\begin{array}{l}43^{1} \\
44\end{array}$ & $\begin{array}{l}\text { M.J. } \\
\text { E.P. }\end{array}$ & $\begin{array}{l}18 \\
12\end{array}$ & $\begin{array}{l}\mathbf{F} \\
\mathbf{F}\end{array}$ & $\begin{array}{l}\mathbf{A} \\
\mathbf{A}\end{array}$ & $3 \cdot 5$ & $\begin{array}{l}5 \cdot 1 \\
8 \cdot 8\end{array}$ & Thyroid adenoma, purpura \\
\hline $45^{1}$ & L.C. & 55 & $\mathbf{F}$ & $\mathbf{D}$ & $3 \cdot 0$ & $4 \cdot 7$ & $\begin{array}{l}\text { Segmental lung collapse, } \\
\text { Hashimoto's disease }\end{array}$ \\
\hline $46^{1}$ & E.A. & 38 & $\mathbf{F}$ & $\mathbf{A}$ & $3 \cdot 6$ & $4 \cdot 4$ & Pulmonary hilar lymphadenopathy \\
\hline 47 & E.W. & 28 & $\mathbf{F}$ & $\mathbf{D}$ & $1 \cdot 6$ & $5 \cdot 7$ & $\begin{array}{l}\text { Acne, depressive psychosis, } \\
\text { albuminuria, oedema }\end{array}$ \\
\hline 48 & E.F. & 28 & $\mathbf{F}$ & D & $3 \cdot 4$ & $5 \cdot 0$ & Pneumonia \\
\hline 49 & G.H. & 16 & $\mathbf{F}$ & $\mathbf{A}$ & $3 \cdot 2$ & $5 \cdot 0$ & Acne \\
\hline $50^{1}$ & J.M. & 31 & $\mathbf{F}$ & $?$ & $3 \cdot 5$ & $4 \cdot 6$ & Epilepsy \\
\hline 51 & E.W. & 20 & $\mathbf{F}$ & D & $3 \cdot 7$ & $4 \cdot 3$ & Diabetes, lupus kidney \\
\hline 52 & L.F. & 13 & $\mathbf{F}$ & $\mathbf{A}$ & 1.9 & $4 \cdot 1$ & Wilson's disease \\
\hline $53^{1}$ & M.J. & 37 & $\mathbf{F}$ & $\mathbf{A}$ & 3.8 & $4 \cdot 6$ & Mitral stenosis \\
\hline $54^{1}$ & E.T. & 54 & $\mathbf{F}$ & $\mathbf{A}$ & $3 \cdot 1$ & $5 \cdot 6$ & Arthritis, L.E. factor \\
\hline
\end{tabular}


TABLE I-continued

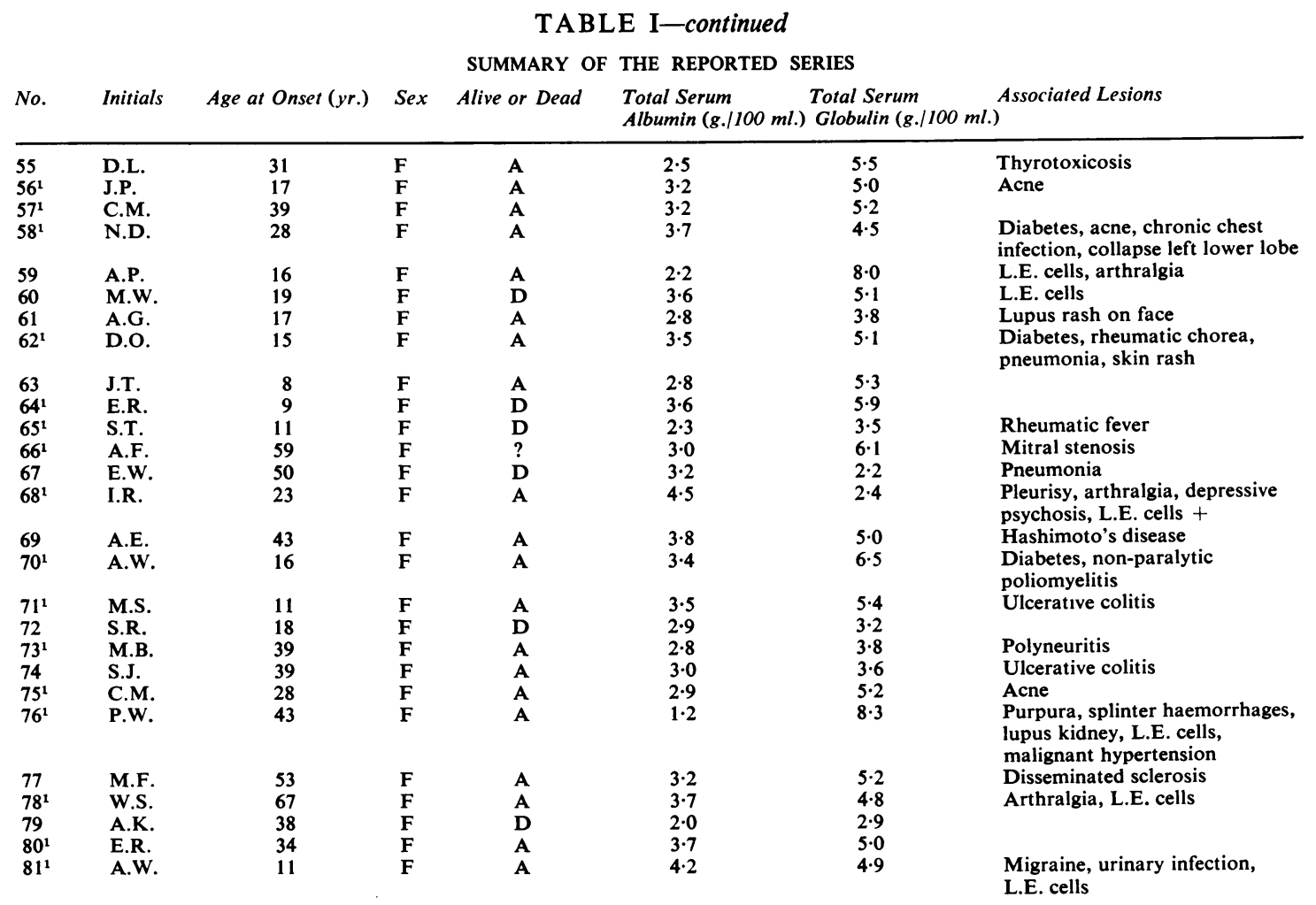

bronchiectasis were all seen. The acute abnormalities -pneumonia and fleeting radiological shadowswere usually seen when the hepatic lesion was active. Recurrent lung infection seemed to be a factor in provoking a relapse of jaundice in two patients. Two patients had pleurisy without radiological evidence of pulmonary consolidation.

Two patients had established chronic rheumatic heart disease (mitral stenosis); one patient had had an attack of rheumatic chorea seven years previously. One other patient had an attack of acute rheumatic fever immediately before the commencement of the jaundice. This patient had raised a antistreptolysin titre, prolonged P.-R. interval in the electrocardiogram, and clinical evidence of carditis.

Renal disorders were observed in 12 patients. Four patients had albuminuria and one of them developed a nephrotic syndrome. Chronic urinary infection was noted in five patients; three others developed a syndrome of polyuria, thirst, hypokalaemia, and renal tubular acidosis and in one of these nephrocalcinosis was demonstrated at necropsy. Three patients showed the glomerular changes of systemic lupus erythematosus and two later developed malignant hypertension.
Five patients had chronic ulcerative colitis. In three patients this preceded the hepatic disease; in one patient the colitis began at the same time as the jaundice and in the other colitis developed while the patient was on steroid drugs given because of the hepatic disease.

A psychotic reaction, apparently out of proportion to the effects of the hepatic lesion, was seen in four patients. In three of these patients a severe depressive psychosis developed early in the disease but in the fourth patient this followed several months of ill health. Two patients had epilepsy. One patient had had disseminated sclerosis diagnosed five years before. A young boy suffered a hemiplegia believed to be due to a cerebral vasculitis. One patient developed polyneuritis. One patient had 'nonparalytic poliomyelitis' at the onset of jaundice.

In three patients diabetes developed before there was clinical evidence of the hepatic lesion. In two other patients diabetes presented well after evidence of liver disease. All patients required insulin, and in three doses greater than 100 units per day were required. One patient had an insulin-binding globulin in the serum. Two patients had Hashimoto's disease before the onset of the hepatic lesion. One 
other patient had a diffuse toxic goitre, treated surgically, the operation being followed by jaundice. There was a past history of thyrotoxicosis treated by drugs in one other patient and one patient with mild myxoedema showed atrophy of the thyroid at necropsy, with accompanying Crookes cell change in the pituitary gland.

\section{HAEMATOLOGICAL FEATURES}

Forty-two of the 81 patients had an anaemia $(\mathrm{Hb}<12 \mathrm{~g}$. per $100 \mathrm{ml}$.) usually normochromic in type. Twenty-one of the patients had a low peripheral white count ( $<4,000$ cells per c.mm.), and in 20 of these the leucopenia was associated with splenic enlargement. High peripheral leucocyte counts ( $>12,000$ per c.mm.) with a polymorphonuclear leucocytosis were seen in eight patients; a high count did not correlate with the severity of the jaundice. Platelet levels below 100,000 per c.mm. were found in 17 of 44 patients. In eight of these patients there was an accompanying leucopenia.

L.E. CELLS A search for L.E. cells was usually made on at least three occasions, using the two-hour clot technique. Positive results were obtained in 10 of the 81 patients only during the active phase of the hepatic disease. Five of the 10 patients had an accompanying arthralgia. Two further patients had the L.E. factor in their serum though showing no L.E. cells. One of these two patients also had arthritis.

The differential agglutination test was positive in eight of 35 patients tested (titre $>1 / 64$ ). Five of those with positive reactions were between the ages of 9 and 17, all with high total globulin levels (3.6 - 7.2 g. \%). With the exception of one patient with spondylitis these patients did not have joint symptoms. A direct Coombs test was performed in 10 patients and in three a positive result $(>1 / 16)$ was found. One of these patients had a mild haemolytic anaemia. The Wassermann reaction was usually anticomplementary.

\section{BIOCHEMICAL FEATURES}

The serum bilirubin level was raised to between 3 and $25 \mathrm{mg}$. \%. Most patients showed only moderate elevations (3-10 $\mathrm{mg} \%$ ).

Hyperglobulinaemia, and in particular, hypergammaglobulinaemia, was conspicuous. Total globulins ranged from 2.4 to $8.8 \mathrm{~g} . \% ; 43$ patients had total globulin levels of $5 \mathrm{~g} . \%$ and over. Levels were high during the active phase and fell with remissions. On electrophoresis, some patients, particularly those with deep jaundice, showed a high, rather narrow, gamma globulin peak, but usually a less homogenous and broader peak resulted from beta and gamma globulin increase. The serum albumin was usually well maintained, although 27 patients had levels less than $3 \mathrm{~g} . \%$. As the disease resolved albumin levels tended to rise as the globulins decreased. Flocculation tests were always strongly positive. There was moderate and sometimes marked elevation of the glutamic oxaloacetic transaminase up to 800 units $/ \mathrm{ml}$.

\section{HEPATIC PATHOLOGY}

Histological material was studied in detail from 46 representative cases although biopsies and necropsies were performed in 81 cases. There were single biopsies in 23, repeated biopsies in 16, biopsy or biopsies followed by post-mortem sections in five and post-mortem sections only in two.

FIBROsIS The group includes patients in various stages of the disease from those with relatively minor changes up to fully developed cirrhosis. They have consequently been divided according to the degree of fibrosis in the most advanced specimen. Because, in the majority of patients, only needle biopsy material is available, there must inevitably be an appreciable element of sampling error and this must be allowed for in the interpretation of the findings. The mildest cases (12 patients) showed areas of reticulin collapse together with increased reticulin around the portal tracts, and, in some cases, the reticulin fibres joined up adjacent portal tracts (group 1, Fig. 5) (cases 8, 10, 12, 13, 36, 38, 46, $53,55,63,68,69)$. The next most severe group (nine patients) showed portal tract enlargment and joining, together with the enclosure of small groups of liver cells in a network of dense reticulin fibres (group II) (Fig. 6) (cases 14, 33, 37, 45, 48, 51, 56, 62, 66). In the next more severe group (15 patients) there were bands of fully developed collagen, with or without additional finer reticulin fibrosis. Nodular regeneration could not be recognized because of the small amount of tissue available. It is probable that there was true cirrhosis in most if not all of these subjects (group III) (Fig. 7) (cases 1, 2, 3, 6, 7, 35, 42, $43,49,50,54,57,58,59,70)$. Finally there were 10 examples of true cirrhosis recognizable in needle, surgical, or post-mortem specimens (group IV) (Fig. 8) (cases 4 (P.M.), 5 (P.M.), 9 (P.M.), 11 (needle and P.M.), 34 (P.M.), 15 (S), 39 (surgical), 40 (P.M.), 60 (P.M.), 67 (needle and P.M.). Of these 10 specimens, eight showed the picture of postnecrotic cirrhosis and one, a needle biopsy, had small regenerative nodules suggesting portal 


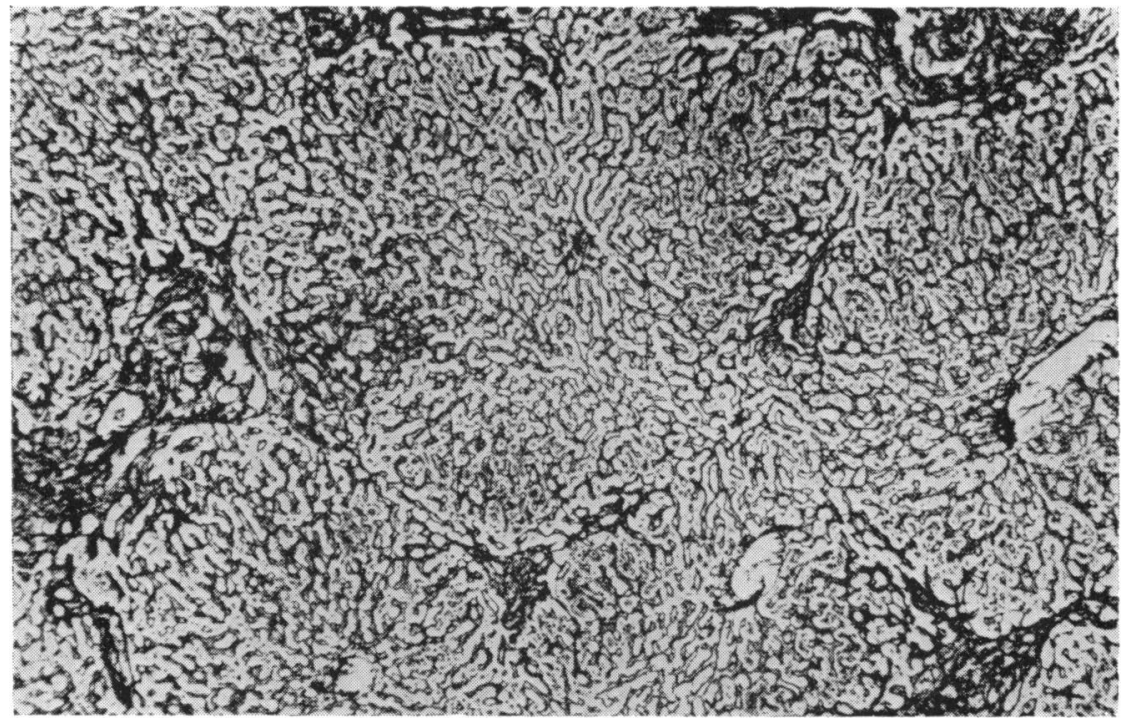

FIG. 5. Group I, case 42:

Fibrosis. There is fibrous

thickening of the portal

tracts which are tending to

join up but lobular

structure is preserved.

Silver impregnation of

reticulin fibres $\times 57$.

FIG. 7. Group III, case

33: Fibrosis. Dense band

of fibrous tissue separates

two liver cell masses.

Silver impregnation $\times 70$.

FIG. 5

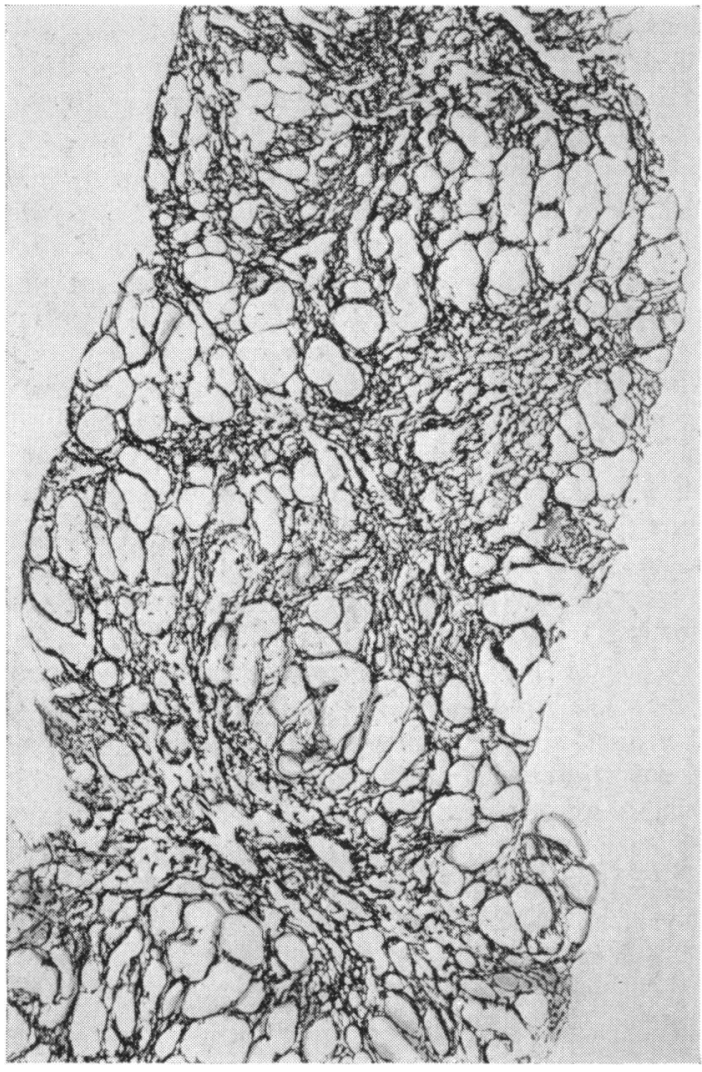

FIG. 6. Group II, case 16: Fibrosis. Three portal tracts have joined up and irregular groups of liver cells are enmeshed botween them. Silver impregnation $\times 100$.

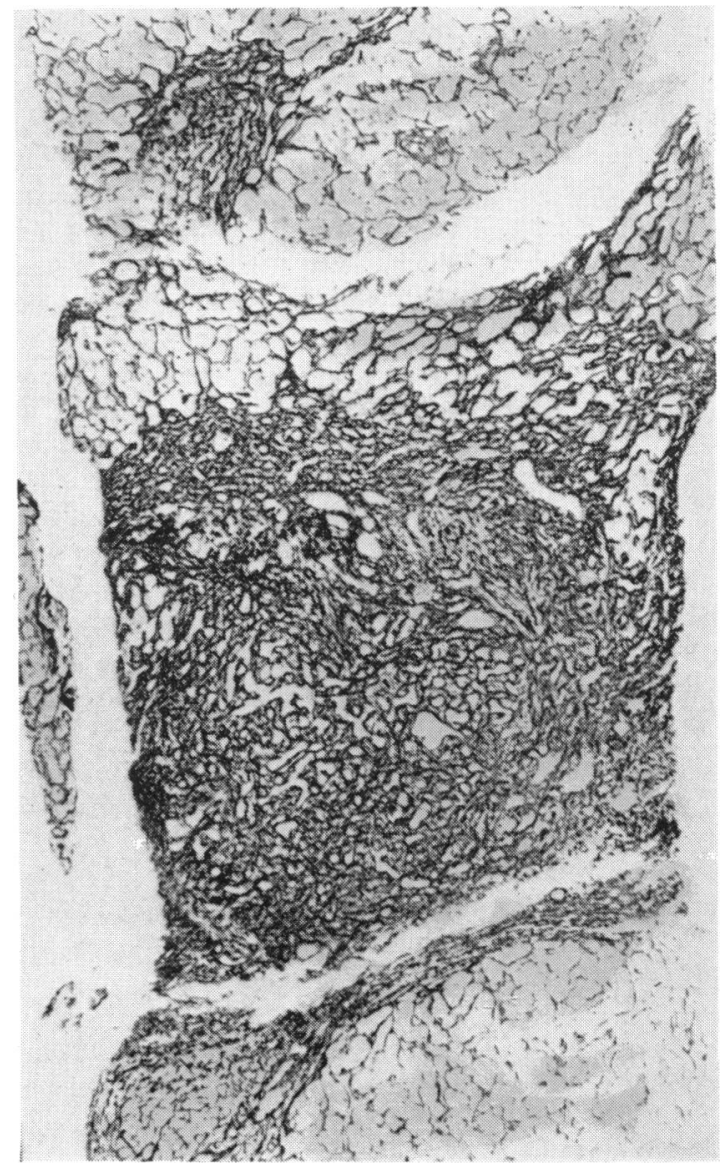

FIG. 7 


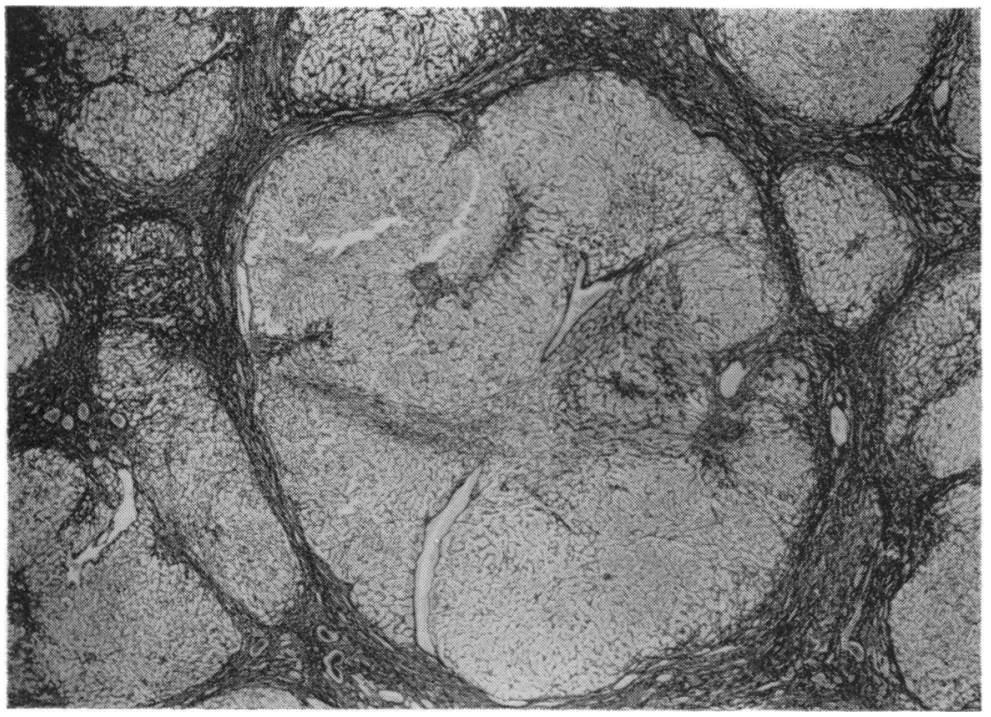

FIG. 8. Group $I V$, case 1I:

Fibrosis. Necropsy section showing

post-necrotic type of cirrhosis.

The regeneration nodules vary

greatly in size and the large one

contains both portal tracts and

central veins.

Silver impregnation $\times 15$.

FIG. 9. Junction of fibrous tissue and liver parenchyma in case 38. Note the heavy cellular infiltration of the former, the irregular edge between them, the hydropic change in the liver cells, and small foci of infiltration among liver cells.

Haematoxylin and eosin $\times 200$.

FIG. 8
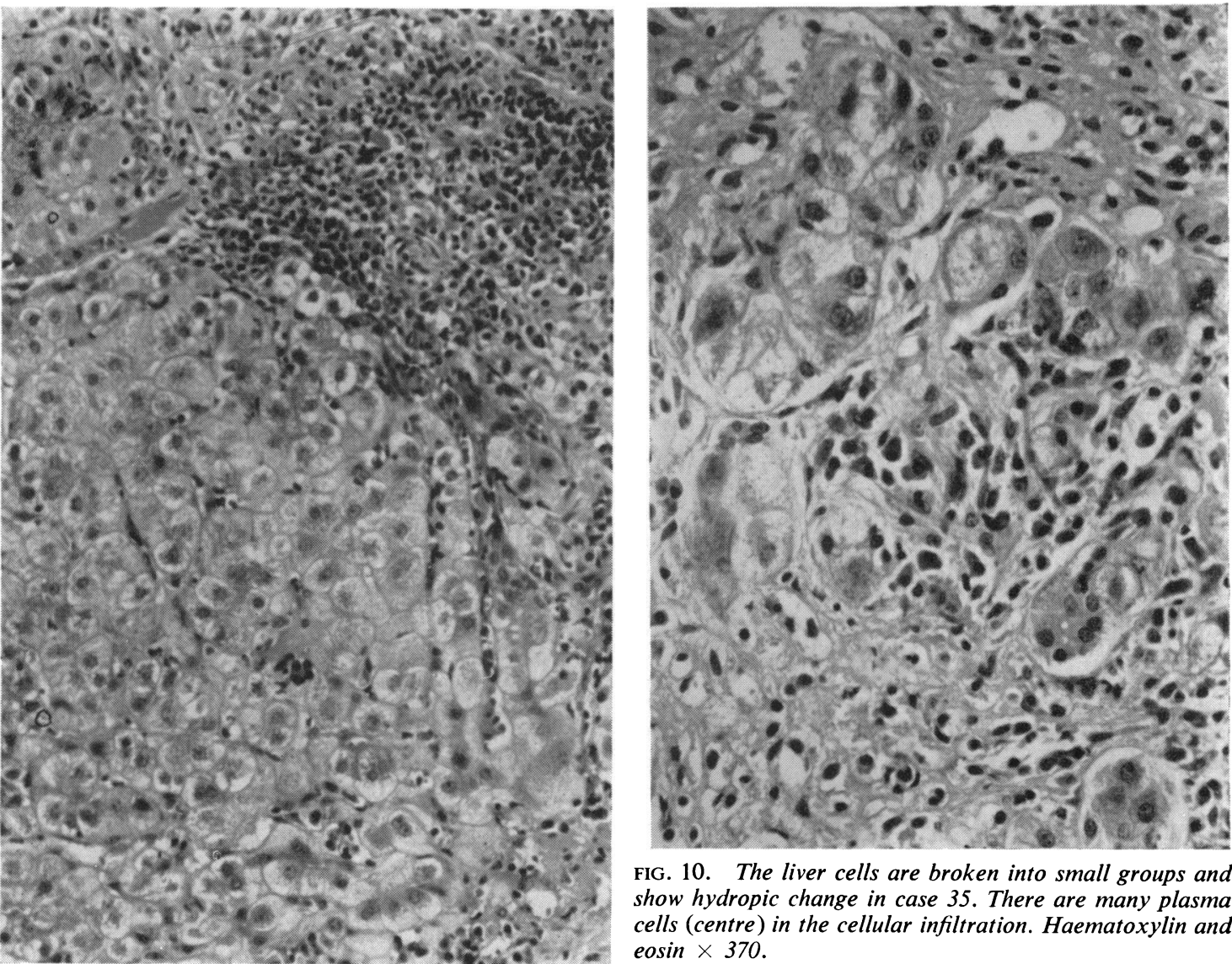

FIG. 10. The liver cells are broken into small groups and show hydropic change in case 35. There are many plasma cells (centre) in the cellular infiltration. Haematoxylin and eosin $\times 370$.

FIG. 9 
cirrhosis but at necropsy a fully developed postnecrotic cirrhosis was present.

The junction between fibrous tissue and liver cells was usually irregular (Fig. 9) and the fibrosis appeared to be actively increasing ( 32 cases). In eight cases there were some parts with a clear-cut, regular edge but other parts were infiltrative; five of these were examples of cirrhosis in post-mortem sections, one was a surgical biopsy of a cirrhosis, and two were needle biopsy examples of grade III fibrosis. One surgical biopsy showed apparently inactive cirrhosis with smooth edges to the regeneration nodules and in five cases (needle biopsies) it was not possible to be certain.

Cellular infiltration Cellular infiltration was present in every specimen, the most frequent cell being the lymphocyte. The infiltration lay mainly in the fibrous tissue of the portal tracts and was dense between 10 and 25 cells per 1,000 square microns. Apart from lymphocytes, plasma cells were always present, usually in appreciable numbers (Fig. 10). No other types of cell were frequent. The mixture of lymphocytes and plasma cells was not always uniform. In 13 out of the 46 cases plasma cells were concentrated at the edge between the fibrous tissue and the liver cells. Two other cell types were seen but only in small numbers: polymorphonuclears in 22 cases and eosinophils in 15 cases. Apart from the fibrous areas, focal collections of lymphocytes and usually plasma cells were seen among the liver cells (Fig. 9). This was seen in 23 out of the 46 cases. No regular correlation could be found between the type of density of the cellular infiltration and the stage of the disease as estimated by the fibrosis.

BILE DUCT PROLIFERATION Slightly increased numbers of small bile ducts were often present in the fibrosed portal tracts. This was seen in 27 cases, was absent in 17, and in two cases there was insufficient tissue to be certain. The degree of bile duct proliferation was slight and not of the degree seen in biliary obstruction.

LIVER CELl DAMAGE Liver cell damage was visible in most cases (Figs. 9 and 10). This took the form of vacuolation of the peripheral part of the cell cytoplasm or hydropic degeneration (Popper and Schaffner, 1957) together with an undue variation in cell size (anisocytosis). An attempt was made to assess the degree of damage in terms of the proportion of liver cells showing hydropic degeneration in the biopsy. There was, however, no apparent correlation between liver cell damage as estimated in this way and the degree of fibrosis. The distribution of damaged cells was also noted in the 33 cases showing hydropic degeneration. In 14 cases degeneration was evenly distributed, in another 12 it was present in the cells near the areas of fibrosis and cellular infiltration, and in seven cases it was focal but the foci were not clearly related to any particular part of the liver.

Hyaline cells and so-called alcoholic hyaline were very rare. Fatty change was equally unusual, being found only five times. Frozen sections were not available, but it is at least safe to assume that no severe degrees of fatty change occurred.

BILE RETENTION In spite of the fact that jaundice was present clinically, bile retention was remarkably infrequent in the biopsies. Only seven cases showed bile retention and in none was it severe.

\section{CORTICOSTEROID TREATMENT}

GENERAL The effects were assessed in 43 patients with good follow-ups. The cases given corticosteroid therapy were not specially selected. Many patients were seen before these drugs were in general use, so that there was a group of 'pre-corticosteroid' cases. Cases in which jaundice and constitutional upset were mild were also not treated but the majority of patients seen later were given corticosteroid therapy.

Oral prednisone or prednisolone was usually employed, initially $30 \mathrm{mg}$. daily in divided doses reducing to a maintenance dose of $5 \mathrm{mg}$. twice or three times daily.

Orally administered corticosteroids were accompanied by an increased sense of well being and the disappearance of pyrexia. Jaundice usually diminished within two or three days, particularly in cases in which it was moderate or severe. Following the initial, and often rapid, decline there was a slower phase, often lasting several weeks or months, during which the serum bilirubin level fell slowly to normal. A significant fall in the serum bilirubin was noted to occur in 42 of the 53 courses of treatment.

Arthralgia and skin rashes, apart from acne, invariably disappeared; serological reactions if positive tended to become less so, the Coombs test in three patients became negative, and the haemolytic anaemia accompanying it in one patient disappeared. In four of five patients diabetes was made worse by steroid drugs and in three of these corticosteroids had to be stopped. Women with previous amenorrhoea noted a return of the menses. A further relapse due to premature diminution in the dose of corticosteroids, or other factors such as intercurrent infection, was always accompanied by a return of amenorrhoea. One patient developed ulcerative 
colitis, and two others with lupus changes in the kidneys, malignant hypertension.

The size of the spleen also tended to diminish, especially when greatly enlarged. Liver size sometimes diminished.

After cessation of therapy 11 patients had clinical and biochemical relapses. In four patients this was severe enough to lead to a restarting of corticosteroid therapy. Side-effects of corticosteroids included mooning and skin striae accompanying a rapid increase in weight. In one patient a sudden and massive increase in weight (28lb. in three weeks) necessitated stopping therapy. Septic skin complaints were seen in six patients, who developed troublesome furunculosis. Four patients developed septicaemia; in three death occurred while they were on corticosteroids, and the other developed fatal septicaemia some months after steroids had been stopped. One patient developed salpingitis while on therapy. One patient died with extensive respiratory moniliasis.

BIOCHEMICAL Transaminases were determined before and after 37 courses of treatment and showed a significant fall in 36 patients. The changes in serum proteins were less impressive. The serum albumin was usually $3 \mathrm{~g}$. or more before the commencement of treatment and on five occasions in five patients there was a significant fall (1g. per $100 \mathrm{ml}$. or more) and on eight occasions in eight patients there was a significant rise in the albumin level. A fall in the globulin level was noted in 31 of the 53 courses with a significant change in the serum globulin pattern on electrophoresis and, in some instances, a return to a normal pattern (Fig. 11).
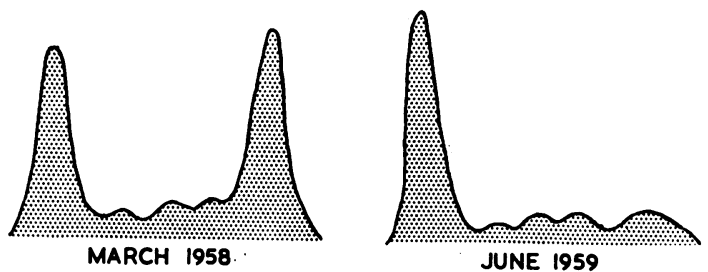

FIG. 11. Electrophoresis of serum proteins before and after prednisolone therapy in case 38. Total protein $8 \cdot 4 \mathrm{~g}$. per ml. (albumin $3 \cdot 2 \mathrm{~g}$. per $\mathrm{ml}$., globulin $5 \cdot 2 \mathrm{~g}$. per $\mathrm{ml}$.) in March 1958. Total protein $6.0 \mathrm{~g}$. per ml. (albumin $3.8 \mathrm{~g}$. per $\mathrm{ml}$., globulin $2 \cdot 2 \mathrm{~g}$. per $\mathrm{ml}$.) in June 1959.

Unfortunately little serial information is available concerning the 38 patients not treated with steroids. These were largely those seen earlier or late in the disease when activity had lessened. Fifteen of those followed have died. Nine patients are still alive, of whom four show a return of biochemical tests to normal and five no change; four of these have been subjected to portacaval anastomosis.
HISTOLOGICAL Histology was assessed for evidence of progress or regression of the disease by the pathologist without knowledge of the treatment given. This was done under three headings: fibrosis, liver cell damage, and cellular infiltration, and the results were scored as better, worse, or no change. Obviously such comparisons are subject to sampling error. In regard to fibrosis, which is necessarily focal, the comparisons have very limited validity. Liver cell damage is sometimes focal but the differing foci are small in size and a comparison between biopsies is probably valid. The same is true of the density of the cellular infiltration.

STEROID-TREATED GROUP From 12 patients treated with steroids multiple sections were available for study. Two patients (nos. 8 and 11) showed no detectable change; two more (nos. 9 and 35) showed deterioration by all three criteria; one (no. 34) showed deterioration of damaged liver cell, and one showed slight increase of fibrosis. On the other hand, one patient (no. 59) showed improvement by all three criteria; two (nos. 43 and 46) improvement in liver cells and infiltrate; two (nos. 53 and 54) showed less fibrosis, and one (no. 46) showed less fibrosis and improvement in the liver cells. In summary, two showed no change, four had deteriorated by one or more criteria, and six had improved by one or more criteria. If changes in fibrosis, which were always slight, are excluded, two showed no change, four improved, and three deteriorated.

UNTREATED GROUP Multiple biopsies were available from eight patients. Two (nos. 48 and 63) showed no change, four (nos. 12, 38, 39, 60) had improved by some criteria (no. 60), of which one had improved in respect of cellular infiltration but had deteriorated in respect of fibrosis. If changes in fibrosis are excluded then two showed no change, four improved, and two deteriorated.

Corticosteroid treatment seemed to be without any constant effect on progress as judged by histological criteria.

\section{PROGNOSIS}

Prognosis was both variable and unpredictable (Fig. 12). There were 26 fatal cases in the 79 patients with adequate follow-up. The average survival time of the fatal cases was similar in males and females, namely, 3.4 years in 12 males and 3.4 years in 14 females. Of the survivors, 17 of the 53 followed up were alive and well six years and longer from the apparent onset of the chronic hepatic lesion; 14 of these 17 patients were women and three of them 


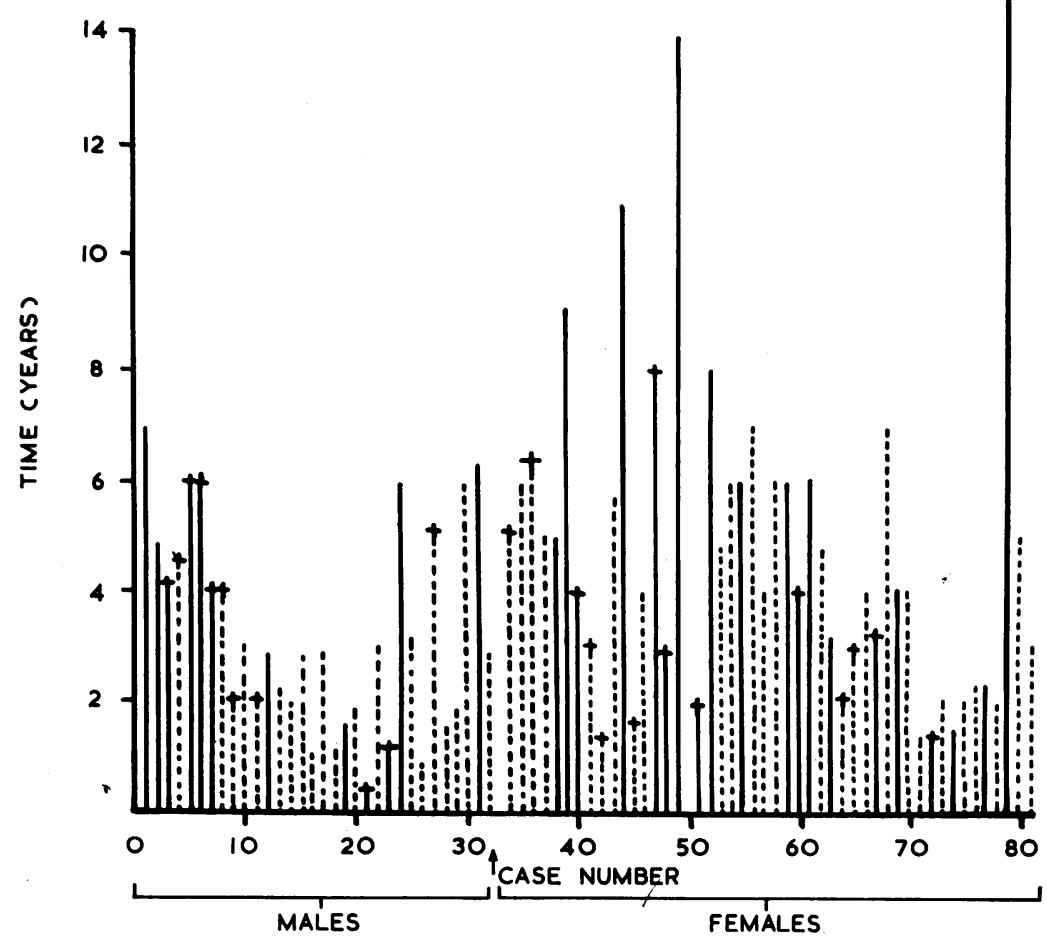

FIG. 12. The duration of survival of the 81 patients. Deaths are marked with a cross. ..... Corticosteroids.

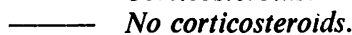

TABLE II

CAUSE OF DEATH IN 26 FATAL CASES

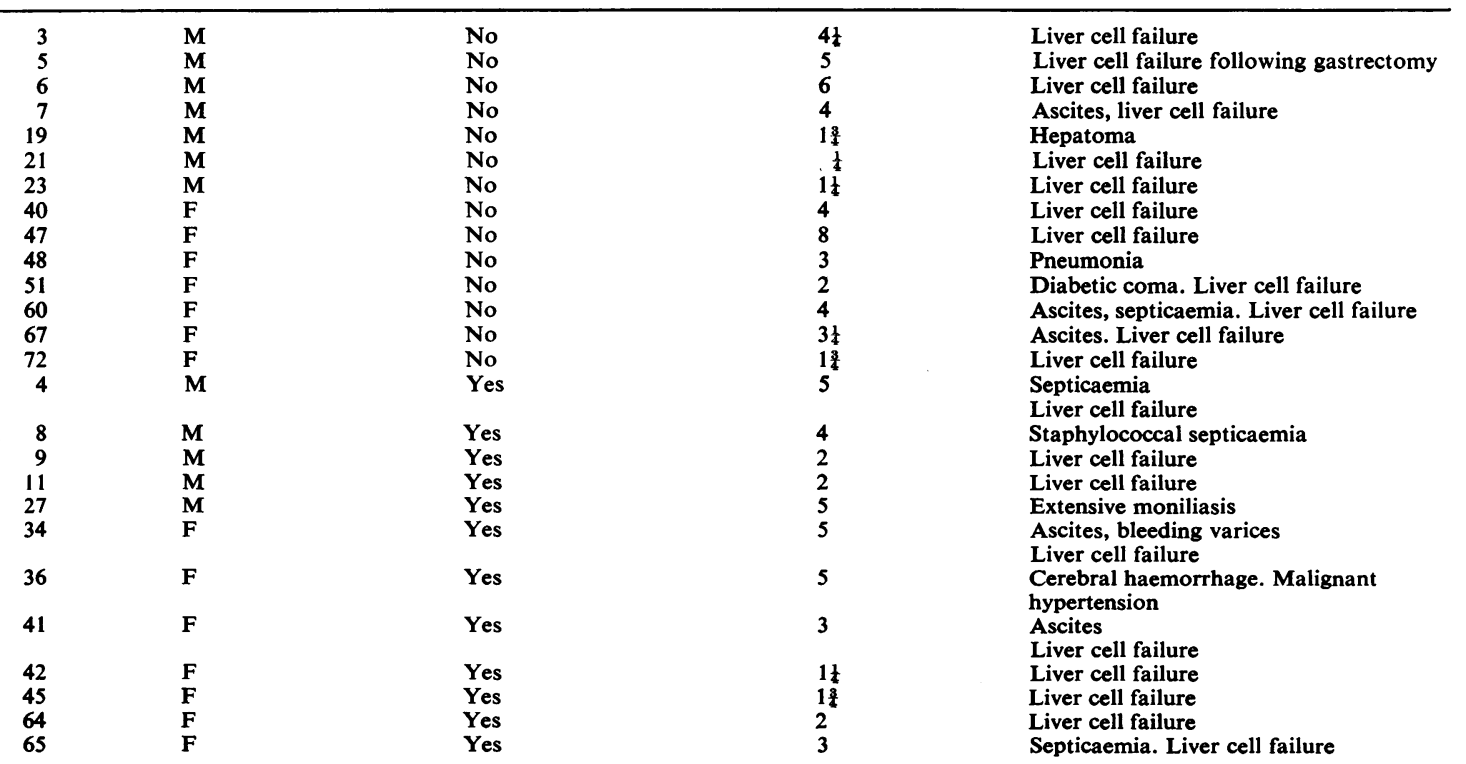


were alive and well over 10 years from the onset. The difficult phase for survival was the first few years of the illness when the liver lesion was active. Twentythree of the 26 patients who died did so within five years and 17 within four years of the onset. Mortality was similar in males $(12: 32)$ and in females $(14: 47)$ but long-term survival was much more commonly seen in women. The mean survival of the 12 fatal cases treated with corticosteroids was $3 \cdot 1$ years. The figures for the 14 fatal cases not treated with corticosteroids was $3 \cdot 5$ years. Corticosteroids did not, therefore, affect the duration of survival of fatal cases.

The vast majority of the 26 deaths were due to liver cell failure with jaundice, fluid retention, and hepatic coma (Table II). In two cases liver cell failure followed operation and diabetic coma, and in only one was it precipitated by oesophageal bleeding. Four patients died from septicaemia, and one from extensive moniliasis. Four of these patients were on steroids at the time of death. One patient with malignant hypertension died of cerebral haemorrhage. The clinical features of the disease were not helpful prognostically. Deep jaundice with grossly disordered liver function tests did not necessarily signify a poor prognosis nor did mild jaundice and compensated liver disease signify a good one. The disease ran an unpredictable course, and many patients returned to good health after having severe jaundice and grossly impaired liver function. Fifteen of the 23 who died had not at any time up to the terminal stage of their illness a bilirubin level greater than $5 \mathrm{mg} . \%$.

\section{DISCUSSION}

The condition we have described has received a number of names. Patients with predominantly hepatocellular jaundice have been female and young (Bearn et al., 1956; Cullinan, 1936; Kelsall, Stewart, and Witts, 1947; Polack, 1937; Saint, King, Joske, and Finckh, 1953; Willocx and Isselbacher, 1961). The association with L.E. cells in the blood has led Mackay and his group to coin the term 'lupoid hepatitis' and this association has been noted by others (Bartholomew, Hagedorn, Cain, and Baggenstoss, 1958 and 1960). Hepatic histological appearances have resulted in the term 'plasma cell hepatitis' (Good, 1956; Page and Good, 1960). The hypergammaglobulinaemia has also received attention (Amberg, 1942; Kunkel, Ahrens, Eisenmenger, Bongiovanni, and Slater, 1951 ; Zimmerman, Heller, and Hill, 1951). Basically, the condition seems similar whether or not L.E. cells, hypergammaglobulinaemia, or plasma cell infiltrates are present or marked.
The term 'juvenile' cirrhosis has therefore been adopted, admitting that a few of our patients are not juvenile and a few may not progress to cirrhosis. This seems preferable to terms such as 'lupoid hepatitis' and 'subacute' or 'chronic hepatitis', as these do little but focus attention on unproven aetiological factors.

Three years ago, 37 female and 15 male patients had been seen, but subsequently a further 16 males and 11 females were observed. The overall female preponderance is therefore not so obvious, and the condition can be diagnosed with assurance in young males. In 23 patients the illness began acutely, presumably related to an attack of viral hepatitis, and this seems to be an important factor in some patients (Page and Good, 1960; Mackay, 1961; Bearn et al., 1956). The histological changes in the liver sometimes suggest viral hepatitis (Jones and Castleman, 1962). The cause of the relentless progression of the disorder is more difficult to understand. In the majority the illness begins insidiously, but without some serological or other test to detect previous virus hepatitis, this remains a possible initiator in these patients also. Other patients with progressive hepatitis, however, do not necessarily show persistent jaundice or hypergammaglobulinaemia, and in them other organs are not involved (Sherlock, 1948; Krarup and Roholm, 1941).

The progressive nature of this disorder might be the result of autoimmunity (Taft, Mackay, and Cowling, 1960). An injurious agent such as the virus of hepatitis is said to render the liver cell or some part of it antigenic. The occasional positive L.E. cell test and the dominant lymphocytic and plasma cell infiltrates seen in the liver support this theory. The cellular infiltrate consisting largely of lymphocytes might represent forbidden 'clones' of cells (Burnett and Fenner, 1949) which are able to damage neighbouring liver tissue because of their antigenicity (Cohen, Ohta, Singer, and Popper, 1960).

The frequency in young women and the deepening of jaundice produced by oestrogens (Bearn et al., 1956) suggest hormonal factors. Pregnancy or the post-puerperal period seemed to be a precipitating event in the onset of jaundice in five of our patients and this has been previously noted (Bartholomew et al., 1958). In one patient, ovarian atrophy coupled with Crookes change in the pituitary and atrophy of the thyroid suggested that, at least in this patient, hormonal factors were important.

The association with other diseases in which autoimmunity is postulated, such as Coombs'-positive haemolytic anaemia and Hashimoto's disease (Roitt and Doniach, 1958) may support this hypothesis. 
Ulcerative colitis may represent the effects of antibodies damaging the colonic mucosa (Calabresi, Thayer, and Spiro, 1961 ; Broberger and Perlmann, 1959), and this has been noted in association with acute juvenile cirrhosis (Willocx and Isselbacher, 1961; Gray, Mackay, Taft, Weiden, and Wood, 1958; Page and Good, 1960; Case Records of the Massachusetts General Hospital, 35101, 1949). In our patients the liver lesion was typical of the whole series. Three patients had symptoms of colitis after there was clinical evidence of chronic liver disease suggesting that the cirrhosis was not the result of the colitis. An immune mechanism could presumably have caused both the hepatic and colonic lesions.

Acute rheumatic fever and chronic rheumatic heart disease, rheumatoid arthritis and spondylitis, all observed in our patients, may also be related to abnormal immune mechanisms. Other writers have noted acute rheumatic fever preceding this type of liver disease (Page and Good, 1960) and arthralgia has been frequently noted.

Renal lesions included albuminuria and glomerular lesions similar to those of systemic lupus erythematosus. The significance of renal infection is difficult to assess. Three of our patients developed a syndrome of acute polyuria, thirst, and hypokalaemia. In one of these patients impaired excretion of an acid load, with nephrocalcinosis at necropsy, supported the diagnosis of renal tubular acidosis. One other patient (case 40) showed nephrocalcinosis at necropsy without previous symptoms of renal disease. Renal tubular acidosis without complicating liver disease has previously been related to autoimmune antibodies (Fourman and McCance, 1955; Greenspan, 1949). Two other patients had a similar clinical syndrome with deficient acidification but here hypokalaemia and urinary infection seemed more likely to be operative. Renal disease complicating this liver disorder is well recognized (Taft et al., 1960; Page and Good, 1960; Mackay, Taft, and Cowling, 1959; Willocx and Isselbacher, 1961).

Hashimoto's disease has been shown in patients with liver disease (Luxton and Cooke, 1956; McConkey and Callaghan, 1960). In our series, one of the two patients with this combination has been reported previously (McConkey and Callaghan, 1960). The three patients reported by these authors were all post-menopausal women with prominent lymphocytic infiltration in the portal zones of the liver as well as in the thyroid. The similarity of the two lesions might indicate a dual autoimmune basis. Other thyroid disorders have previously been recorded, as has diabetes which we noted in five of our patients (Mackay et al., 1959; Case Records of the Massachusetts General Hospital, 30491, 1944).

Acute and chronic chest infection either preceding or accompanying the hepatic disorder is not infrequently recorded (Heller, Zimmerman, Rozengvaig, and Singer, 1956; Case Records Massachusetts General Hospital, 26371, 1940, 34402,1948; Polack, 1937). This may perhaps result from a poor antibody response to the infecting agent associated with hypergammaglobulinaemia, as is seen in myelomatosis (Kenny and Moloney, 1957). The generalized lymphadenopathy seen in two patients and the prominent splenomegaly might represent abnormal reticulo-endothelial activity with the production of antibodies. One of our patients without chest infection showed a prominent right hilar adenitis of unknown aetiology.

Epilepsy and psychotic changes may be seen in some patients with systemic lupus erythematosus (Harvey, Shulman, Tumulty, Conley, and Schoenrich, 1954; Jessar, Lamont-Havers, and Ragan, 1953; Larson, 1961). Polyneuritis may result from an abnormal immune mechanism, also from disseminated sclerosis (Raskin 1955; Frick, 1954). One example of each of these lesions was seen in our patients.

Other lesions such as diabetes, skin rashes, chronic pulmonary and serous membrane lesions, including arthralgia. could represent a disturbance of immunity. In systemic lupus erythematosus, arthralgia, skin lesions, renal and pulmonary disorders are common (Harvey et al., 1954; Larson, 1961).

The histological condition of the liver did not correlate well with the duration of the clinical disorder. Some patients with established cirrhosis (group III and IV fibrosis) have a history of less than one year's illness. This suggested that the disease might be present before the patient showed recognizable clinical features.

Some authors feel that this lesion is chronic systemic lupus erythematosus in which, for some reason, hepatic damage is predominant (Aronson and Montgomery, 1959; Mackay, 1961). Damage to the liver of any severity is, however, rare in systemic lupus erythematosus. Mackay et al. (1959) found evidence of mild histological abnormalities in 11 of 19 patients with systemic lupus erythematosus and more severe lesions including cirrhosis, 'hepatitis', and fibrosis in five others. In our series positive L.E. cell tests were found rarely, and no practical differences in clinical course or response to corticosteroid therapy existed between patients with and without this abnormality (Heller et al., 1956). A positive L.E. test may only indicate abnormal immunological responses, and this form of chronic liver disease cannot be equated with systemic lupus erythematosus. Progressive liver disease can develop where there is agammaglobulinaemia and hence when antibody formation is severely restricted (Good 
and Page, 1960). An autoimmunity mechanism does not explain the particular age and sex so frequently encountered. Infective hepatitis moreover does not usually show any predilection for either sex. Young patients, and in particular, women, are not known to be specially liable to progressive damage following hepatitis, although this may apply to menopausal and post-menopausal women (Alsted, 1947; Jersild, 1947; Klatskin, 1958).

Corticosteroid drugs inhibit immune and inflammatory mechanisms so it seemed reasonable to use prednisone therapy and a beneficial effect is said to occur (Last, 1957; Mackay, 1961; Page and Good, 1960). Our results confirm clinical and biochemical improvement. The dramatic initial fall in the serum bilirubin from moderately or greatly elevated levels was similar to that seen in patients with virus hepatitis (Williams and Billing, 1961). Raised serum transaminase levels also fell (O'Brien, Goble, and Mackay, 1958). The effects on the altered serum proteins were also marked in some patients and, after several months of therapy the protein pattern sometimes returned to normal. Usually, however, even after a complete clinical remission, abnormal serum proteins, positive flocculation tests, and slightly elevated transaminase levels persisted.

Some patients were completely refractory to corticosteroid therapy, most usually the deeply jaundiced subjects with evidence of severe liver cell failure. There appeared to be no essential difference in this group from others responding satisfactorily. Only two patients showed a complete biochemical return to normal. In one of these the liver biopsy is also normal; the other patient has a post-necrotic cirrhosis. A complete return to normal of the clinical and histological picture has been reported both with and without steroid therapy but it is unusual (Page and Good, 1960).

On cessation of therapy relapse of the clinical condition and biochemical changes occurred in some patients even when complete clinical and biochemical control had been achieved. This made it difficult to decide when corticosteroids should be stopped. These drugs affect growth, and troublesome side-effects include facial disfigurement, particularly important in young people, so therapy must be stopped as soon as possible. Cessation after about one year's therapy was attempted in those with good clinical and biochemical response. Return of ill health and biochemical relapse were indications for restarting. Even after continuous therapy for four years and a return of liver function tests (with the exception of the flocculation tests and transaminases) to normal, relapse has followed stopping the drug. Efforts should, however, be made at yearly intervals to stop corticosteroids.
The effect on hepatic histology was less satisfactory. Last (1957) noted that five of nine liver biopsy sections from treated cases showed no dramatic changes. In our series, examination of serial specimens suggests that gradual progression to post-necrotic cirrhosis continues. The mechanical disadvantages of advancing fibrosis and nodular regeneration with resultant portal hypertension were not affected.

A controlled trial of corticosteroid drugs would be difficult as therapy makes the patients feel better and they lose their jaundice. We have therefore been reluctant to embark on this project. Corticosteroid therapy does not prolong life (Table II) and should be reserved for those who feel ill. Such patients seem to be living more useful and happier lives while receiving corticosteroids.

Histological improvement was not impressive, however. The active stage of the liver cell injury rather than fibrosis and cirrhosis is the salient problem and steroids may limit this aspect. The patient with liver cell disease receiving corticosteroids often shows severe side-effects, perhaps related to slower hepatic metabolism (Peterson, 1960). Severe 'mooning', acne, and cutaneous striae may follow only 10 to $15 \mathrm{mg}$. prednisolone daily. Severe weight gain in one patient necessitated cessation of therapy. The severe relapse which followed did not respond to further treatment and ended fatally.

Slowing of growth might be deleterious, but in fact the adolescent spurt in growth seems greater than normal (Sherlock, 1958). Sepsis, however, remains a distinct problem. Five patients have died from septicaemia or infection, four of them while still on corticosteroids. Minor septic complications were also troublesome and these patients may develop acne even before treatment.

Corticosteroid therapy always makes diabetes worse and insulin requirements rise. Control of diabetes may be difficult and in three patients therapy had to be stopped. One patient, though having an insulin-binding globulin in the serum, was not benefited by steroids and insulin requirements did not fall (Oakley, Field, Sowton, Rigby, and Cunliffe 1959).

This type of hepatic disease has a poor prognosis and eight of the 14 patients recorded by Mackay et al. (1959) have died. Willocx and Isselbacher (1961) noted that 20 of 30 women had died, the survival period ranging from six months to seven years. The 11 men fared better, the average survival being five years. In contrast are the four patients who received corticosteroids and after several years showed no clinical evidence of liver disease (Page and Good, 1960). Bearn et al., (1956) noted an average survival of seven years but death within 10 years was the rule. 
Our patients, both male and female, survived about four years. Men fared less well than women not only in a less complete response to steroids but in showing a higher percentage of fatalities. In contrast, Willocx and Isselbacher (1961) comment on a particularly poor prognosis in females; however, fewer patients in the American series were given corticosteroids.

\section{SUMMARY}

Eighty-one patients (32 male and 49 female), who were not alcoholics, with jaundice of hepato-cellular type lasting longer than three months, have been studied. Forty-nine patients were under 21 years of age. In 23 patients there was some evidence that the disease began as acute viral hepatitis. In the others the disease was insidious in onset or was related to pregnancy, a surgical operation, or seemed to commence with an illness related to disease in an organ remote from the liver. The physical signs included icterus and hepatosplenomegaly accompanied in female patients by amenorrhoea. The complications associated with portal hypertension, namely, the appearance of oesophageal varices, bleeding from varices, and ascites were of late onset. Hepatic histology showed liver cell damage, massive hepatic fibrosis progressing to post-necrotic cirrhosis, and a prominent portal zone infiltrate of lymphocytes and plasma cells. Serum changes included hypergammaglobulinaemia and raised transaminase values with markedly positive seroflocculation tests.

Associated features included skin rashes (22), arthralgia and arthritis (9), pulmonary infection, collapse and infiltration (13), rheumatic fever, rheumatic heart disease (4), renal disorders including albuminuria (4), systemic lupus nephritis (3), urinary infection (4), syndrome of polyuria, thirst, and hypokalaemia (3), malignant hypertension (2), psychosis (4), endocrine disorders, especially diabetes mellitus and thyroid disease (11), lymphadenopathy (2), epilepsy and cerebral vasculitis (3), ulcerative colitis (5), and haemolytic anaemia (1).

L.E. cells were found in the blood of 10 patients, and the serum differential agglutination test was positive in eight patients. The serum Wassermann reaction was invariably anticomplementary.

Corticosteroid therapy in $\mathbf{4 3}$ patients resulted in an increased feeling of well-being, return of the menses in females, and the diminuation and disappearance of jaundice and relief of certain associated features, such as arthralgia. Serum transaminase values usually fell. Alterations in the serum proteins were less common and improvement in hepatic histology was uncertain.
Prognosis was extremely variable and at the outset unpredictable. Death occurred most frequently in the first four years after recognition of the disorder. Twenty-six patients died, the average duration of life being 3.5 years. The 12 patients treated with corticosteroid lived an average of $3 \cdot 1$ years and the 14 not given this therapy 3.5 years from diagnosis. Longer survival was seen, particularly in female patients. Hazards of corticosteroid therapy included aggravation of diabetes, skin sepsis, and septicaemia. The usual side-effects of corticosteroids -striae, mooning of the face, and weight gainwere marked even with modest doses of these drugs. Prolongation of life was not demonstrated by therapy.

The aetiology of this disorder is discussed with special reference to its relation to virus hepatitis, to systemic lupus erythematosus, and to other disturbances of immunity.

\section{REFERENCES}

Alsted, G. (1947). Studies on malignant hepatitis. Amer. J. med. Sci., 213, 257-267.

Amberg, S. (1942). Hyperproteinemia associated with severe liver damage. Proc. Mayo. Clin., 17, 360-362.

Aronson, A. R., and Montgomery, M. M. (1959). Chronic liver disease with a 'lupus erythematosus-like syndrome'. Arch. intern. Med., 104, 544-552.

Bartholomew, L. G., Cain, J. C., Baggenstoss, A. H., and Hagedorn, A. B. (1960). Further observations on hepatitis and cirrhosis in young women with positive clot tests for lupus erythematosus. Gastroenterology, 39, 730-736.

- Hagedorn, A. B., Cain, J. C., and Baggenstoss, A. H. (1958). Hepatitis and cirrhosis in women with positive clot tests for lupus erythematosus. New Engl. J. Med., 259, 947-956.

Bearn, A. G., Kunkel, H. G., and Slater, R. J. (1956). The problem of chronic liver disease in young women. Amer. J. Med., 21, 3-15.

Broberger, O., and Perlmann, P. (1959). Autoantibodies in human ulcerative colitis. J. exp. Med., 110, 657-674.

Burnett, F. M., and Fenner, F. (1949). The Production of Antibodies, 2nd ed. Macmillan, Melbourne.

Calabresi, P., Thayer, W. R., Jr., and Spiro, H. M. (1961). Demonstration of circulating antinuclear globulins in ulcerative colitis. J. clin. Invest., 40, 2126-2133.

Case Records of Mass. Gen. Hosp., No. 26371. (1940). New Engl. J. Med., 223, 422-427.

No. 30491. (1944). lbid., 231, 771-774.

- No. 34402. (1948). Ibid., 239, 519-524.

, No. 35101. (1949). Ibid., 240, 384-388.

Cohen, S., Ohta, G., Singer, E. J., and Popper, H. (1960). Immunocytochemical study of gamma globulin in liver in hepatitis and postnecrotic cirrhosis. J. exp. Med., 111, 285-293.

Cullinan, E. R. (1936). Idiopathic jaundice (often recurrent) associated with subacute necrosis of the liver. St. Bart. Hosp. Rep., 69, 55-142.

Fourman, P., and McCance, R. A. (1955). Tetany complicating the treatment of potassium deficiency in renal acidosis. Lancet, 1 , 329-331.

Frick, E. (1954). Zur Serologie der multiplen Sklerose. Klin. Wschr. 32, 450-452.

Good, R. A. (1956). Plasma-cell hepatitis and extreme hypergammaglobulinemia in adolescent females. Amer. J. Dis. Child., 92 508-509.

- and Page, A. R. (1960). Fatal complications of virus hepatitis in two patients with agammaglobulinemia. Amer. J. Med., 29, 804-810.

Gray, N., Mackay, I. R., Taft, L. I., Weiden, S., and Wood, I. J. (1958) Hepatitis, colitis, and lupus manifestations. Amer.J.dig. Dis., 3, 481-491. 
Greenspan, E. M. (1949). Hyperchloremic acidosis and nephrocalcinosis. The syndrome of pure 'lower nephron' insufficiency. Arch. intern. Med. 83, 271-291.

Harvey, A. M., Shulman, L. E., Tumulty, P. A., Conley, C. L., and Schoenrich, E. H. (1954). Systemic lupus erythematosus: review of the literature and clinical analysis of 138 cases. Medicine (Baltimore), 33, 291-437.

Heller, P., Zimmerman, H. J., Rozengvaig, S., and Singer, K. (1956). The L. E.-cell phenomenon in chronic hepatic disease. New. Eng. J. Med., 254, 1160-1165.

Jersild, M. (1947). Infectious hepatitis with subacute atrophy of the liver. An epidemic in women after the menopause. Ibid., 237, 8-11.

Jessar, R. A., Lamont-Havers, R. W., and Ragan, C. (1953). Natural history of lupus erythematosus disseminatus. Ann. intern. Med., 38, 717-731.

Jones, W. A., and Castleman, B. (1962). Liver disease in young women with hyperglobulinemia. Amer. J. Path., 40, 315-329.

Kelsall, A. R., Stewart, A., and Witts, L. J. (1947). Subacute and chronic hepatitis. Lancet, 2, 195-198.

Kenny, J. J., and Moloney, W. C. (1957). Multiple myeloma; diagnosis and management in a series of 57 cases. Ann. intern. Med., 46, 1079-1091.

Klatskin, G. (1958). Subacute hepatic necrosis and postnecrotic cirrhosis due to anicteric infections with the hepatitis virus. Amer. J. Med., 25, 333-358.

Krarup, N. B., and Roholm, K. (1941). The development of cirrhosis of the liver after acute hepatitis, elucidated by aspiration biopsy. Acta. med. scand., 108, 306-331.

Kunkel, H. G., Ahrens, E. H., Jr., Eisenmenger, W. J., Bongiovanni, A. M., and Slater, R. J. (1951). Extreme hypergammaglobulinemia in young women with liver disease of unknown etiology. J. clin. Invest., 30, 654.

Larson, D. L. (1961). Systemic Lupus Erythematosus. Churchill, London.

Last, P. M. (1957). The treatment of active chronic infectious hepatitis with ACTH (corticotrophin) and cortisone. Med. J. Aust., 1, 672-676.

Luxton, R. W., and Cooke, R. T. (1956). Hashimoto's struma lymphomatosa. Diagnostic value and significance of serumflocculation reactions. Lancet, 2, 105-109.

McConkey, B., and Callaghan, P. (1960). Thyroiditis and cirrhosis of liver. Ibid, 1, 939-941.
Mackay, I. R. (1961). The problem of persisting destructive disease of the liver. Gastroenterology, 40, 617-626.

- Taft, L. I., and Cowling, D. C. (1959). Lupoid hepatitis and the hepatic lesions of systemic lupus erythematosus. Lancet, 1, 65-69.

Naish, J. M. (1960). Autoclastic (lupoid) hepatitis. Brit. J. clin. Pract. 14, 749-754, 760.

Oakley, W., Field, J. B., Sowton, G. E., Rigby, B., and Cunliffe, A. C., (1959). Action of prednisone in insulin-resistant diabetes. Brit. med. J., 1, 1601-1606.

O'Brien, E. N., Goble, A. J., and Mackay, I. R. (1958). Plasmatransaminase activity as an index of the effectiveness of cortisone in chronic hepatitis. Lancet, 1, 1245-1249.

Page, A. R., and Good, R. A. (1960). Plasma-cell hepatitis, with special attention to steroid therapy. Amer. J. Dis. Child., 99, 288-314.

Peterson, R. E. (1960). Adrenocortical steroid metabolism and adrenal cortical function in liver disease. J. clin. Invest., 39, 320-331.

Polack, E. (1937). Chronic hepatitis in young persons, with or without intermittent jaundice. Acta. med. scand., 93, 614-621.

Popper, H., and Schaffner, F. (1957). Liver: Structure and Function. p. 203. McGraw-Hill, New York, and London.

Raskin, N. (1955), Antibrain antibodies in multiple sclerosis. Arch. Neurol. Psychat. (Chicago), 73, 645-655.

Roitt, I. M., and Doniach, D. (1958). Human auto-immune thyroiditis: serological studies. Lancet, 2, 1027-1033.

Saint, E. G., King, W. E., Joske, R. A., and Finckh, E. S. (1953). The course of infectious hepatitis with special reference to prognosis and the chronic stage. Aust. Ann. Med., 2, 113-127.

Sherlock, S. (1948). Post-hepatitis cirrhosis. Lancet, 1, 817-822.

(1958). Discussion on endocrine changes in liver disease. Proc. roy. Soc. Med., 51, 359-361.

- (1961). In Wilson's Disease-Some Current Concepts, edited by J. M. Walshe and J. N. Cumings, p. 182. Blackwell, Oxford.

Taft, L. I., Mackay, I. R., and Cowling, D. C. (1960). Autoclasia: a perpetuating mechanism in hepatitis. Gastroenterology, 38, 563-566.

Waldenström, J. (1950). Leber Blutproteine und Nahrungseiweiss Stof wechs.- krh. Sonderband XV Tagung, Bad Kissingen, p. 8

Williams, R., and Billing, B. H. (1961). Action of steroid therapy in jaundice. Lancet, 2, 392-396.

Willocx, R. G., and Isselbacher, K. J. (1961). Chronic liver disease in young people. Amer. J. Med., 30, 185-195.

Zimmerman, H. J., Heller, P., and Hill, R. P. (1951). Extreme hyperglobulinemia in subacute hepatic necrosis. New. Engl. J. Med., 244, 245-249. 